\title{
ÁCIDOS ORGÂNICOS EM RAÇÕES DE POEDEIRAS COMERCIAIS
}

\author{
SUPPLEMENTATION WITH ORGANICS ACIDS IN DIET OF LAYING HENS
}

\author{
Nilce Maria Soares Queiroz Gama ${ }^{1}$ Maria Beatriz Cardoso de Oliveira ${ }^{2}$ \\ Elizabeth Santin ${ }^{3}$ Ângelo Berchieri Junior ${ }^{4}$
}

RESUMO

\begin{abstract}
Desenvolveu-se este trabalho com o objetivo de avaliar o efeito de ácidos orgânicos adicionados à dieta de aves de postura. Foram utilizadas 75 frangas Isa Brown de 4 meses de idade, divididas em três grupos experimentais (I, II e III) de 25 aves cada e avaliadas por um período de 8 semanas. $O$ grupo $I$ recebeu ração tratada com ácidos orgânicos por quatro semanas, enquanto que o grupo II recebeu ração com ácidos orgânicos por oito semanas, permanecendo o grupo III sem a suplementação de ácidos orgânicos durante todo o período experimental, sendo definido como grupo controle. Ao final do experimento, foram observados dados de produção de ovos, peso das aves, qualidade e peso de ovos. Os resultados demonstraram que a produção de ovos foi melhor nas aves tratadas com o aditivo acidificante (grupos I e II), sendo que os acidificantes também proporcionaram um melhor peso corporal nas aves $(P<0,05)$. A qualidade e o peso dos ovos não foram afetados pela suplementação desses aditivos.
\end{abstract}

Palavras-chave: poedeiras, ácidos orgânicos, produção de ovos, qualidade de ovo, desempenhos.

\section{SUMMARY}

Organic acids are incorporated to the poultry feeds to control Salmonella and moulds. However, there is little information about its effect on the performance of laying hens. Thus, this work was undertaken to study the incorporation of organic acids on the laying hens eggs production. They were placed in 3 groups of 25 animals. Birds in group I were fed with ration containing organic acid for 4 weeks; birds in group II received ration containing organic acid for 8 weeks, and birds in group III were fed with ration without organic acid (Control group). Egg production, body weight, egg weight and egg quality were the analyzed parameters. With base on the results of the incorporation of organic acid into the feed for 4 or 8 weeks improved the egg production, and the body weight $(P>0.05)$ but the egg weight and egg quality were not affected.

Key words: laying hens, organics acids, eggs production, egg quality, performance.

\section{INTRODUÇÃO}

A utilização de ácidos orgânicos como aditivos em rações para aves tem crescido muito nos últimos anos. A aplicabilidade dessas substâncias está associada ao seu efeito inibidor sobre o desenvolvimento microbiano e sua influência sobre a disponibilidade de matérias primas. Diversos autores (HINTON \& LINTON, 1988; IBA \& BERCHIERI, 1995; OLIVEIRA et al., 1996) têm sugerido o uso de ácidos orgânicos em dietas de aves, com o objetivo de diminuir a contaminação por bactérias. A utilização desse aditivo também tem sido recomendada com o intuito de controlar a presença de fungos nas rações (DIXON \& HAMILTON, 1981 e DARI $\boldsymbol{e} t$ $\boldsymbol{a l}$., 1995), pois, de acordo com BARTOV et al. (1982), o uso de grãos fungados, mesmo sem a presença de micotoxinas, podem comprometer o desempenho de frangos de corte, uma vez que os fungos são capazes de produzir lipases que atuam nos cereais, diminuindo o seu valor nutricional. Este fato foi demonstrado por BARTOV (1985), o qual observou que a presença de ácidos propiônico e sórbico foi eficiente na prevenção do decréscimo do teor de gordura em rações contendo grãos fungados. CHERRINGTON et al. (1991) acreditam que os ácidos comprometem algumas funções vitais dos microorganismos, como transporte de substrato, $\mathrm{pH}$ citoplasmático e síntese de macromoléculas. PENZ (1991) refere de que os ácidos orgânicos reduzem o pH do estômago, além de aumentar a atividade de certas enzimas e melhorar a digestibilidade de alguns nutrientes. Um estudo realizado por IZAD et al. (1990) demonstrou que a acidificação da dieta de

${ }^{1}$ PqCIII, Instituto Biológico, Laboratório de Patologia Avícola de Bastos, Aluna de Pós-graduação da UNESP, Jaboticabal, Av. Gaspar Ricardo, 1700, 17690-000, Bastos, SP. E-mail: besantin@fcav.unesp.br. Autor para correspondência.

${ }^{2}$ Diretora técnica do IGI, Vinaland Laboratories.

${ }^{3}$ Aluna de Pós-graduação da UNESP, Jabotical.

${ }^{4}$ Professor, Departamento de Patologia Veterinária, UNESP, Jaboticabal. 
frangos de corte com ácido propiônico proporcionou melhor rendimento de carcaça e a redução no número total de coliformes no duodeno, jejuno e íleo das aves suplementadas. No entanto, CAVE et al. (1984) encontraram redução no consumo de ração e no ganho de peso de frangos de corte suplementados com acidificantes na dieta. PENZ et al. (1993) concluíram que se fazem necessários mais estudos para esclarecer a ação desses aditivos e sua aplicabilidade prática em dietas para aves, tendo visto que os resultados podem variar dependendo da idade e do peso da ave, além, é claro, do tipo de dieta e do tempo de suplementação com o produto. Observando que poucos trabalhos fazem referência à utilização desses ácidos em dietas de poedeiras, o presente trabalho foi desenvolvido visando determinar o efeito da adição de ácidos orgânicos no desempenho de poedeiras comerciais.

\section{MATERIAL E MÉTODOS}

Foram alojadas, em gaiolas individuais $(25 \times 40 \times 35 \mathrm{~cm}), 75$ frangas Isa Brown de 20 semanas de idade no biotério experimental do Laboratório de Patologia Avícola do Instituto Biológico de Bastos/SP. Durante um período de 3 semanas, os animais permaneceram em adaptação ambiental e, na $24^{\text {a }}$ semana de vida das aves, iniciou-se o período de avaliação que teve duração de oito semanas, no qual elas foram divididas em três grupos (I, II e III) de 25 aves cada, sendo que cada ave constituía uma unidade experimental. Os animais do grupo I receberam ração tratada com um produto à base de ácidos orgânicos (Laynex ${ }^{a}$ ) por quatro semanas, enquanto que o grupo II continuou recebendo o mesmo tratamento durante oito semanas, e o grupo III não recebeu tratamento com ácidos orgânicos, permanecendo como controle durante todo o período experimental (Tabela 1).

Durante todo o experimento, as aves foram submetidas ao manejo usual em avicultura de postura, sendo alimentadas com ração balanceada oriunda de uma fábrica de ração comercial. $\mathrm{O}$ acidificante, composto pelos ácidos fumárico $(0,5 \%)$, lático $(5,13 \%)$, cítrico $(5,44 \%)$ e ascórbico $(1,2 \%)$, foi incorporado à ração em misturador tipo "Y" numa proporção de $0,05 \%$. O delineamento utilizado foi inteiramente casualizado e os dados de produção de ovos, peso das aves, peso e qualidade de ovos (unidades Haugh) foram analisados em 3 períodos: $1^{\circ}$ período (referente a $24^{\mathrm{a}}$ até a $28^{\mathrm{a}}$ semana de vida das aves), $2^{\mathrm{o}}$ período (29aㅡ $32^{\mathrm{a}}$ semana de vida das aves), $3^{\mathrm{o}}$ período ( $24^{\mathrm{a}}$ até $32^{\mathrm{a}}$ semana de vida das aves), e submetidos a uma análise de variância, pelo teste de F, em nível de $95 \%$ de probabilidade.
Tabela 1 - Grupos experimentais.

Grupo experimental Tempo de suplementação com Laynex®

\begin{tabular}{cc}
\hline I & 4 semanas \\
II & 8 semanas \\
III & Sem suplementação \\
\end{tabular}

\section{RESULTADOS E DISCUSSÃO}

Os dados de produção de ovos (Tabela 2) demonstraram que a adição de ácidos orgânicos à dieta aumentou a produtividade das aves, o que pode ser observado nos grupos I e II nos quais a média para esse parâmetro se apresentou superior $(\mathrm{P}<0,05)$, quando comparado ao grupo III, durante os três períodos de avaliação. Esses resultados sugerem que a acidificação da dieta pode proteger as aves de microorganismos que prejudicam o desempenho, o que foi bem documentado por CHERRINGTON et al.(1991), WALDROUP et al. (1995) e DARI $\boldsymbol{e}$ t al. (1995). O grupo I, apesar de ter uma produção de ovos melhor que o controle, apresentou uma queda na produção no $2^{\circ}$ período de avaliação, referente ao momento em que parou de receber a suplementação, fato este que está de acordo com HUMPHREY \& LANNING (1988), os quais também observaram que esses aditivos devem ser fornecidos durante todo o período de criação. Os resultados observados, no presente experimento, talvez, possam ser explicados pelas constatações de BURNELL et al. (1988) e PENZ (1991) os quais sugerem que os ácidos orgânicos podem favorecer a ativação enzimática gastrointestinal, aumentando a digestibilidade dos nutrientes da dieta e, dessa forma, podem influenciar na resposta do animal a diferentes agentes bacterianos, conseqüentemente, melhorando o seu desempenho zootécnico.

Quando são avaliados os dados de peso corporal (Tabela 3), pode-se observar que os grupos

Tabela 2 - Porcentagem semanal de produção de ovos para cada grupo experimental.

\begin{tabular}{lccc}
\hline & \multicolumn{3}{c}{ Tratamento } \\
& I & II & III \\
& & & \\
\hline & & & \\
$1^{\text {o }}$ período $(24-28$ semanas de idade $)$ & $94,9^{\mathrm{a}}$ & $93,8^{\mathrm{a}}$ & $85,1^{\mathrm{b}}$ \\
$2^{\text {o }}$ período $(29-32$ semanas de idade $)$ & $88,6^{\mathrm{b}}$ & $94,2^{\mathrm{a}}$ & $79,8^{\mathrm{c}}$ \\
Período Total $(24-32$ semanas de idade) & $91,5^{\mathrm{a}}$ & $94,0^{\mathrm{a}}$ & $82,2^{\mathrm{b}}$
\end{tabular}

Médias seguidas de letras diferentes diferem significativamente $(\mathrm{P}>0,05)$. 
Tabela 3 - Peso médio das aves (g) segundo o grupo experimental.

\begin{tabular}{cccc}
\hline \multirow{2}{*}{ Semana de vida } & \multicolumn{3}{c}{ Grupo experimental } \\
& I & II & III \\
\cline { 2 - 4 } & & & \\
\hline & 1538 & 1540 & 1515 \\
24 & $1520^{\mathrm{a}}$ & $1547^{\mathrm{a}}$ & $1502^{\mathrm{b}}$ \\
32 & $1534^{\mathrm{a}}$ & $1527^{\mathrm{a}}$ & $1352^{\mathrm{b}}$ \\
\hline
\end{tabular}

Médias seguidas de letras diferentes diferem significativamente $(\mathrm{P}>0,05)$.

I e II, também, apresentaram maior peso das aves quando comparados ao grupo controle. Assim, podese constatar que a acidificação da dieta exerce um efeito protetor, sugerindo que, à semelhança do que foi observado para produção de ovos, seja uma resposta às melhores condições do trato gastrointestinal proporcionadas pelos ácidos orgânicos. Esse fato conduz à hipótese de que esses aditivos poderiam estar colaborando para manutenção do bom estado físico das aves e estão de acordo com PATTEN \& WALDROUP (1988) que demonstraram um melhor ganho de peso em frangos de corte suplementados com $1 \%$ de ácido fumárico na dieta. Apesar disso, CAVE (1984), fazendo referência a outros autores, cita que o nível de $6 \mathrm{~g} / \mathrm{kg}$ de ácido propiônico na dieta pode causar redução na ingestão de alimentos e no ganho de peso de frangos de corte, sugerindo que esses ácidos comprometem a palatabilidade da dieta, reduzindo o consumo das aves.

Não foi observada diferença significativa $(\mathrm{P}>0,05)$ para média de unidades Haugh, nos diferentes grupos do presente experimento apresentados na tabela 4. A qualidade interna de ovos, medida por unidades Haugh (GARCIA, 1991), está ligada à nutrição, linhagem e idade da ave, bem como à temperatura de armazenagem dos ovos (BRAKE, 1995); dessa forma, tendo pouca correlação com a presença de acidificantes na dieta. Na tabela 5, é apresentado

Tabela 4 - Médias de Unidades Haugh dos ovos produzidos nos diferentes grupos experimentais.

\begin{tabular}{cccc}
\hline \multirow{2}{*}{ Período da colheita } & \multicolumn{3}{c}{ Grupo experimental } \\
\cline { 2 - 4 } & I & II & III \\
& & & \\
\hline & & 78,6 & 78,9 \\
24 semana & 78,8 & 82,2 & 85,2 \\
32 semana & 86,4 & 94,6 & 91,6 \\
& 97,1 & & \\
\hline
\end{tabular}

Tabela 5 - Peso médio dos ovos (g) para os diferentes grupos experimentais.

\begin{tabular}{cccc}
\hline \multirow{2}{*}{ Período da colheita } & \multicolumn{3}{c}{ Grupos experimentais } \\
& I & II & III \\
\cline { 2 - 4 } & & & \\
\hline $24^{\underline{a}}$ semana & 58,8 & 57,7 & 55,2 \\
$28^{\underline{a}}$ semana & 54,9 & 53,6 & 55,1 \\
$32^{\underline{a}}$ semana & 57,1 & 58,3 & 54,8 \\
& & & \\
\hline
\end{tabular}

o peso médio dos ovos, parâmetro que, segundo BRAKE (1995), está mais relacionado à idade, genética e tamanho da ave, de forma que esta poderia ser a explicação para que não houvesse diferença entre os diferentes grupos experimentais.

\section{CONCLUSÕES}

Os resultados obtidos neste estudo permitem afirmar que, nas condições experimentais utilizadas, a adição de ácidos orgânicos apresenta um efeito positivo sobre a produção de ovos e peso das aves, todavia, não interferem na qualidade interna dos ovos e no peso dos ovos.

\section{FONTE DE AQUISIÇÃO}

a- Laynex: QUINABRA - Química Natural Brasileira. São José dos Campos, SP.

\section{REFERENCIAS BIBLIOGRÁFICAS}

BARTOV, I. Comparative effects of antifungal compounds on the nutritional value of diets containing moldy corn for broiler chicks. Poultry Science, v.64, p.1236-38, 1985.

BARTOV, I., PASTER,N., LISKER,N. Nutritional value of moldy grains for chicks. Poultry Science, v.61, p.2247, 1982.

BRAKE, J. Pontos importantes de manejo no incubatório para uma boa eclosão. IN: CONFERÊNCIA APINCO'95 DE CIÊNCIA E TECNOLOGIAS AVÍCOLAS, 1995, Curitiba, PR. Anais... Curitiba : APINCO, 1995. 149p. p.49-53.

BURNELL, T.W., CROMWELL,G.L., STAHLY, T.S. Effects of dried whey and copper sulfate on the growth responses to organic acid in diets for weanling pigs. J Animal Science, v.66, p.1100-1112, 1988.

CAVE, N.A.G. Effect of dietary propionic and lactic acids on feed intake by chicks. Poultry Science, v.63, p.131-134, 1984.

CHERRINGTON, C.A., HINTON, M., PEARSON, G.R, et al. Short-chain organic acids at $\mathrm{pH}$ 5,0 kill Escherichia coli and Salmonella spp. without causing membrane pertubation. J Appl Bacteriol, v.70, p.161-164, 1991. 
DARI , R.L., JOST, H.C., FREITAS, T.S., et al. Efeito da aplicação de ácidos orgânicos sobre o desenvolvimento fúngico e as alterações do valor nutritivo do milho com alto teor de umidade. IN: CONFERÊNCIA APINCO'95 DE CIÊNCIA E TECNOLOGIAS AVÍCOLAS, 1995, Curitiba, PR. Anais... Curitiba : APINCO, 1995. 213p. p.13.

DIXON, R.C., HAMILTON, P.B. Evaluation of some organic acids as mold inhibitors by measuring $\mathrm{CO} 2$ production from feed and ingredients. Poultry Science, v.60, p.2182-88, 1981.

GARCIA, E.A. Importância da genética no desempenho de poedeiras. IN: CURSO TÉCNICO EM MANEJO DE POEDEIRAS COMERCIAIS. 1991, Campinas, SP. Anais... Campinas : APINCO, 1991. 271p. p.1-23.

HINTON, M.H., LINTON, A.H. Control of Salmonella infections in broiler chickens by the acid treatment of their feed. Vet Rec, v.123, p.416-421, 1988.

HUMPHREY, T.J., LANNING, D.G. The vertical transmission of salmonellas and formic acid treatment of chicken feed. A possible strategy for control. Epidemiology and infection, v.100, p.43-49, 1988 .

IBA, A.M., BERCHIERI Jr., A. Studies on use of formic acidpropionic acid mixture (Bio-Add ${ }^{\mathrm{TM}}$ ) to control experimental Salmonella infection in broiler chickens. Avian Pathology, v.24, p.303-311, 1995.
IZAD, A.L., TIDWELL,N.M., THOMAS, R.A., et al. Effect of buffered propionic acid in diets on the performance of broiler chicken and on microflora of the intestine and carcass. Poultry Science, v.69, p.818, 1990.

OLIVEIRA, E.; BERCHIERI Jr., A.; SILVA, et al.. Uso de ácidos graxos de cadeia curta no controle de Salmonella em rações de aves. IN: CONFERÊNCIA APINCO'96 DE CIÊNCIA E TECNOLOGIAS AVÍCOLAS, 1996, Curitiba, PR. Anais... Curitiba : APINCO, 1996. 210p. p.83.

PATTEN, J.D., WALDROUP, W. Use of organic acids in broiler diets. Poultry Science., v.67, p.1178, 1988.

PENZ Jr, A.M. Hipótesis que justifican el uso de acidos organicos en las dietas para aves e cerdos. Avicultura Professional, v.9, p.46, 1991.

PENZ Jr, A.M, SILVA, A.B., RODRIGUES, O. Ácidos orgânicos na alimentação de aves. IN: CONFERÊNCIA APINCO'93 DE CIÊNCIA E TECNOLOGIAS AVÍCOLAS, 1993, Santos, SP. Anais... Santos : APINCO, 1993.286p. p.111-119.

WALDROUP, A., KANIAWATO, S., MAUROMOUSTAKOS, A. Performance characteristics and microbiological aspects of broiler fed diets supplemented with organic acids. Journal of Food Protection, v.58, p.482-489, 1995.

Ciência Rural, v. 30, n. 3, 2000. 